\title{
Supporting carers of people with dementia: what is effective?
}

\author{
Graham A. Jackson \& Debbie Browne
}

\begin{abstract}
Carer stress is well documented, especially in those caring for individuals with dementia. A recommendation of all national dementia strategies is to provide excellent support and information to informal carers of people with dementia. NICE guidance suggests that a range of tailored interventions, including psychological input, psychoeducation and training courses, should be offered to reduce caregiver burden and stress, although good-quality outcome-based evidence is lacking. $0 n$ the basis of a narrative review of the literature, we describe individual and multicomponent carer support packages and discuss their evidence base, reflecting on outcomes for carers. Multicomponent interventions have the best evidence for effectiveness.
\end{abstract}

\section{LEARNING OBJECTIVES}

- Consider the risks of both physical and psychological harm experienced by carers of people with dementia (often referred to as carer burden or caregiver burden)

- Be aware of the interventions available for the support of carers of people with dementia

- Consider the evidence for the effectiveness of these interventions and be aware of the limitations of the evidence

\section{DECLARATION OF INTEREST}

None

Caring for a relative or friend with dementia is often described as burdensome (Acton 2001) and it can have an impact on carers' physical health (Pinquart 2003; Zhu 2015) and anxiety levels (Cooper 2007). In addition to providing care for people with dementia, health and social care services offer support for their carers, to improve outcomes for both and to reduce carer burden. Interventions to aid this group of carers include general carer support, education, formal approaches to care and respite, as well as multicomponent interventions (a combination of different types of intervention). But availability of these interventions varies nationally, and evidence of their efficacy is at best mixed, with considerable heterogeneity in results.
Reviewing the effectiveness of interventions for carers of people with dementia is not easy - mixed results from heterogeneous studies challenge the generalisability of findings and make it difficult to make evidence-based decisions regarding appropriate and timely support for carers. Furthermore, studies of such interventions are fraught with methodological difficulties, including poor quality (Acton 2001), lack of conceptual clarity of outcome measures (e.g. 'burden', which has subjective and objective measures), overlap between intervention types, poor definition of interventions, and small samples that often do not include men or ethnic minorities.

The purpose of this article is to provide an updated overview of the evidence base for interventions that are principally aimed at carers of patients with dementia. It is important to recognise, as pointed out by Gitlin and colleagues (2015), that most studies are carried out separately from the care system and may not be reflected in real-world practice.

\section{Method}

Our review method is shown in online Fig. DS1. In essence, we searched MEDLINE, CINAHL, PsycINFO, the Cochrane Database, Social Care Online and Applied Social Sciences Index and Abstracts (ASSIA) for completed studies of all interventions principally aimed at carers of people with dementia. We excluded meta-analyses and reviews, and studies that scored $<3$ on a fivecriteria quality assessment: this left us with 56 studies, the findings of which we discuss here. In keeping with similar reviews (e.g. Acton 2001; Cooper 2012), we categorised interventions into eight discrete groups: counselling and support; education; psychology; occupational therapy; formal approaches to care; telecare; multicomponent; and other.

\section{Results}

\section{Counselling and support}

Counselling and support groups are informal, mutually supportive and often run by the third sector (the voluntary sector).
Graham A. Jackson is Professor of Dementia Care at the Alzheimer Scotland Centre for Policy and Practice, University of the West of Scotland. He has been National Clinical Dementia Advisor to the Scottish Government since May 2014 and was appointed to the Alzheimer Europe Advisory Panel in 2015. Debbie Browne is a consultant old age psychiatrist at Forth Valley Royal Hospital, Larbert. She has a particular interest in liaison psychiatry. Correspondence Professor Graham Jackson, University of the West of Scotland, Hamilton Campus, Hamilton ML3 0JB, UK. Email: graham.jackson@uws.ac.uk

\section{Copyright and usage} (C) The Royal College of Psychiatrists 2017. 
Carers anecdotally report strong benefits from peer support of others 'in the same boat' as them. Often, counselling is provided in settings outside of health and social care services, which may increase accessibility.

Counselling and support groups have been shown to benefit carers in a number of ways, including reducing burden (Chien 2008; Wang 2011), ameliorating depressive symptoms (Ulstein 2007; Mittleman 2008) and improving quality of life. There is also evidence to suggest improvements in carers' self-rated health and greater overall satisfaction with the caregiving role (Mittlemann 2007). Comparative studies between existing support groups in different settings (i.e. day hospital and third-sector groups) show no statistically demonstrated benefits of one over the other (Bartfay 2013). More structured counselling interventions delivered over a fixed period of time (Joling 2012) anecdotally reduce carer burden, but have not significantly demonstrated benefit. Perhaps this suggests that a more flexible, less prescriptive approach is better.

\section{Educational interventions}

Educational interventions primarily aim to impart knowledge or skills to help carers in their caregiving role. Dementia education is a priority in the UK and most post-diagnostic follow-up includes a component of psychoeducation. However, evidence is mixed (Table 1) and larger studies (Kurz 2010; de Rotrou 2011) failed to demonstrate any benefit in their measured outcomes.

Although psychoeducation may not reduce depressive symptoms in carers, other benefits have been demonstrated in smaller studies, including increased confidence in caring (Ducharme 2011), reduced burden (Chien 2008), increased competence (Hepburn 2007) and an improvement in mental health (Dias 2008).
The current 'one size fits all' approach to education groups needs to change - they should be culturally sensitive, and may need to be gender specific. Many published trials have failed to reflect this. Male carers may benefit from an approach based more on problem-solving, for example.

\section{Psychology}

The National Institute for Health and Care Excellence (2006) recommends that carers who experience psychological distress as a result of caring for someone with dementia should be offered psychological therapy by a specialist practitioner. Group-based cognitive-behavioural therapy (CBT) has demonstrated positive results (Losada 2011) in modifying carers' dysfunctional thoughts and a small but significant benefit in reducing depression. Time is of the essence for many carers - although longer, intensive interventions work, many carers simply cannot commit the time to them. Shorter CBT sessions (Márquez-González 2007) and 2-week intensive CBT (Gitlin 2010) have also demonstrated benefit on anxiety and depressive symptoms, as has a manual-based coping strategy (Livingston 2013, 2014).

\section{Formal approaches to care}

This includes appropriate care management, care programming and use of specialist nurses to deliver care. Formal care management involves one clearly identified member of health or social care staff who coordinates care throughout the patient's and carer's journey. Early assessment and identification of problems can trigger appropriate care pathways, often guided by a protocol followed by the care manager in collaboration with the carer. The proposed benefits include improved communication between health and social care services, screening of carers for mental health problems and early access to

Evidence base for psychoeducation of carers of people with dementia

\begin{tabular}{|c|c|c|c|c|}
\hline Study & $n$, intervention/control & Intervention & Outcome measured & Results \\
\hline Kurz et al, 2010 & $156 / 136$ & 7 fortnightly group sessions & Depression, QoL, time spent caregiving & No significant differences \\
\hline de Rotrou et al, 2011 & $79 / 78$ & 12 weekly group sessions & Depression & No significant difference \\
\hline Ducharme et al, 2011 & $62 / 49$ & 7 weekly group sessions & $\begin{array}{l}\text { Confidence, self-efficacy, coping } \\
\text { ability }\end{array}$ & $\begin{array}{l}\text { Greater confidence, self- } \\
\text { efficacy and coping ability }\end{array}$ \\
\hline Chien \& Lee, 2008 & $44 / 44$ & Workshop, 12 sessions over 6 months & OoL, burden, level of social support & $\begin{array}{l}\text { Reduced burden and increased } \\
\text { QoL }\end{array}$ \\
\hline Dias et al, 2008 & $41 / 40$ & $\begin{array}{l}1 \text { visit per fortnight for } 6 \text { months } \\
\text { minimum }\end{array}$ & $\begin{array}{l}\text { Overall mental health, burden, distress } \\
\text { due to problem behaviours }\end{array}$ & $\begin{array}{l}\text { General mental health } \\
\text { improved, no change in burden }\end{array}$ \\
\hline Hepburn et al, 2007 & $30 / 22$ & $\begin{array}{l}12 \text { hours of training (6 fortnightly } \\
\text { sessions), group based }\end{array}$ & Competence, mastery & $\begin{array}{l}\text { Both increased compared with } \\
\text { waiting-list control }\end{array}$ \\
\hline
\end{tabular}

QoL, quality of life. 
treatment, well-coordinated planned support, timely identification of potential crises, and more organised collaborative care (Lam 2010). Continuity of staff is key, but in reality very difficult to achieve (Spijker 2011). Additionally, this approach may be too prescriptive for most carers - consequently, most studies do not show statistically demonstrable benefits.

To encourage more collaborative care between caregivers and health professionals, Simpson et al (2006) developed caregiver-held care records, with sections for completion by carers, families and health professionals. Use of the record was associated with reduced carer strain, but did not improve carer knowledge of dementia overall, nor did it improve health outcomes for carers. However, this study was completed before the introduction of widespread cholinesterase inhibitors for dementia in the UK, and at a time when patients with dementia were often referred late in their diagnosis, so the carers may have been under significant strain for a prolonged period. The authors postulate that caregiver-held records may be of greater benefit to patients and carers in the earlier stages of diagnosis.

An exploratory analysis of data (Connor 2008) examined the significance of a number of variables in a nurse-led care management programme. While use of a care manager to explore care options in general was not associated with an improvement in caregiver mastery, specific approaches, such as assessment of the home environment, were.

Fortinsky et al (2009) looked at the effect on patient outcomes and carers of a dementia care consultation intervention for family caregivers that included a targeted, carer-held care plan, counselling and collaboration with the carers' general practitioner. The rate of admission to hospital or a care home was twice as high among controls than among actively managed patients: the difference was small but approached significance. Carers who were more satisfied with the intervention showed the greatest improvement in self-efficacy, but there were no significant differences specifically on burden or depression, perhaps as the small sample meant that the study was insufficiently powered to identify small but significant change.

\section{Telecare}

Distance-based interventions, using telephones and other technology, have become increasingly used in recent years. Use of technology to provide carer support may be more convenient for the carers, save money for both carers and providers, and eliminate travel and the need for extra support for the patient while the carer is away. A summary of the evidence is given in Table 2 .

\section{Telephone interventions}

The most studied distance-based interventions are those delivered by telephone, probably because telephones are readily available, cheap and carers do not require training to use them. Results on the benefits of telephone interventions are promising, although some studies are of suboptimal quality and involve small numbers. Tremont et al (2008) showed that a telephone-based intervention providing psychoeducation, emotional support and direction of carers to appropriate services was significantly beneficial in reducing caregiver burden and reactions to problem behaviours of

TABLE 2 Evidence base for distance-based support for carers of people with dementia

\begin{tabular}{|c|c|c|c|c|}
\hline Study & $n$, intervention/control & Intervention & Outcome measured & Results \\
\hline Winter \& Gitlin, 2007 & $58 / 45$ & $\begin{array}{l}\text { 6-months: telephone support } \\
\text { group }\end{array}$ & Burden, depression, personal gains & No significant difference \\
\hline van Mierlo et al, 2012 & $46 / 8$ & 20 weeks: telephone coaching & Competence, mental health & $\begin{array}{l}\text { Increased competence, } \\
\text { improved mental health }\end{array}$ \\
\hline $\begin{array}{l}\text { Gallagher-Thompson et } \\
\text { al, } 2010\end{array}$ & $40 / 36$ & 12 weeks: skills-training DVD & Positive affect, depression, stress & $\begin{array}{l}\text { Positive affect significantly } \\
\text { increased, stress decreased }\end{array}$ \\
\hline Tremont et al, 2008 & $32 / 28$ & 12 months: telephone & $\begin{array}{l}\text { Depression, burden, reaction to problem } \\
\text { behaviours of dementia }\end{array}$ & $\begin{array}{l}\text { Lower perceived burden, less } \\
\text { severe reaction to problem } \\
\text { behaviours }\end{array}$ \\
\hline Finkel et al, 2007 & $23 / 23$ & 6 months: computer based & $\begin{array}{l}\text { Depression, burden, health behaviours, } \\
\text { social support }\end{array}$ & No significant effects \\
\hline Gant et al, 2007 & $17 / 15$ & $\begin{array}{l}12 \text { weeks: video/workbook/ } \\
\text { telephone }\end{array}$ & $\begin{array}{l}\text { Self-efficacy, positive and negative } \\
\text { emotions of caring, upset relating to } \\
\text { target complaints }\end{array}$ & $\begin{array}{l}\text { Both interventions improved } \\
\text { measured outcomes but video } \\
\text { condition not superior }\end{array}$ \\
\hline Tremont et al, 2015 & 133/107 & $\begin{array}{l}6 \text { months: family intervention } \\
\text { telephone support compared } \\
\text { with simple telephone support }\end{array}$ & $\begin{array}{l}\text { Depression, burden, reaction to problem } \\
\text { behaviours of dementia }\end{array}$ & $\begin{array}{l}\text { Improvement in depression } \\
\text { ratings and in reactions to } \\
\text { problem behaviours }\end{array}$ \\
\hline
\end{tabular}


dementia, identified as a main contributor to caregiver stress. Furthermore, fewer depressive symptoms were reported in those randomised to the telephone intervention compared with controls, although this did not reach statistical significance (this may in part have reflected that those recruited to the study had lower baseline depression scores than in comparative studies). A more recent study by the same group demonstrated that a more refined family-based telephone intervention reduced depression and reactions to behaviour problems compared with more conventional telephone support (Tremont 2015). In contrast, a telephone coaching intervention (van Meirlo 2012) was shown to have a significant large effect (0.96) on carers' mental health complaints (measured using the General Health Questionnaire) and effects were greater when combined with day care compared with day care alone.

With regard to specifically targeting depressive symptoms, a randomised controlled trial (RCT) (Glueckauf 2012) showed superiority of telephone CBT over face-to-face treatment, although the sample was particularly small $(n=7)$ and involved African American caregivers only. Group-based telephone support may also be effective (Winter 2007). Using conference calling technology, small groups 'met' weekly to share coping strategies, including cognitive reframing and practical approaches to organising care routines, and to provide each other with social support. Although there was no difference in overall depression scores at 6 months, older carers appeared to benefit more from the intervention, perhaps, as the study's authors suggest, because of greater baseline levels of social isolation (there was no significant difference in baseline depression scores). However, older carers also participated in significantly fewer sessions than younger ones, and as with any 'high tech' intervention that requires an initial period of learning, there are concerns that lack of participation may be attributed to difficulties in using the technology by the older group.

\section{DVD support}

Multimedia (DVD) training programmes have also received some interest. In one study (GallagherThompson 2010), a DVD intervention using roleplay and narration to illustrate managing problem behaviours of dementia and provide education and strategies for preparing for placement was compared with a control 'information only' DVD. While both groups showed a decrease in depressive symptoms on the Centre for Epidemiologic Depression Scale (CES-D), the difference between them was not statistically significant, although those in the intervention group did score significantly higher on the positive affect subscale than controls. Stress related to problem behaviours was also significantly reduced in those using the intervention DVD. Such benefits were not seen in a study (Liddle 2012) that used a brief DVDbased training programme focusing on memory and communication strategies between caregivers and the person with dementia. Although a greater proportion of carers who received the intervention reported improved perceptions related to their caregiving role (46\% v. $13 \%$ of controls), the difference did not reach significance. Nor was there a significant impact on burden.

A preliminary RCT (Gant 2007) comparing telephone-based psychoeducation with combined telephone and video support in male caregivers ( $n=15$ and 17 respectively) showed benefit in both groups in terms of increased positive affect, decreased negative affect and improved general health (measured by total number of subjective complaints reported), although no superiority of the combined intervention was demonstrated.

\section{Internet and web-based interventions}

Given that many homes now have internet access via computers and mobile phones, the use of the internet to deliver carer support seems promising. Finkel et al (2007) developed a support intervention using screen phones with computer access to a website to deliver individual education sessions and group-based support for 6 months. Similar to other technology-based interventions, they did not observe a significant benefit when compared with an information-only control group, although in stratifying the results it did appear that those who were most depressed significantly benefitted the most, suggesting that timely delivery of this type of intervention should be considered. However, a systematic review (Boots 2014) concluded that internet interventions were not supported by highquality research evidence, and called for further research.

\section{Multicomponent interventions}

Multicomponent interventions consist of two or more different types of intervention. They might include components of support, counselling, education, respite care and psychology. There is a moderate positive evidence base for multicomponent interventions (Table 3), although there is still debate regarding which components and in which combination are most effective. Trials in this area are often larger, perhaps because recruitment is easier as the intervention is more representative of day-to-day practice. 
TABLE 3 Evidence base for multicomponent interventions for carers of people with dementia

\begin{tabular}{|c|c|c|c|c|}
\hline Study & $\begin{array}{l}n \text {, intervention/control } \\
\text { or by intervention arm }\end{array}$ & Intervention & Outcomes measured & Results \\
\hline Dröes et al(2006) & $94 / 34$ & $\begin{array}{l}6 \text { months: education meetings, } \\
\text { discussion groups, social activities }\end{array}$ & $\begin{array}{l}\text { Subjective carer burden, } \\
\text { carer competence }\end{array}$ & $\begin{array}{l}\text { Small effect size on } \\
\text { subjective burden }\end{array}$ \\
\hline Belle et al (2006) & $\begin{array}{l}\text { Hispanic: } 106 / 106 \\
\text { White: } 113 / 106 \\
\text { Black: 104/107 }\end{array}$ & $\begin{array}{l}7 \text { months: didactic instruction, role- } \\
\text { play, problem-solving, skills training, } \\
\text { stress management techniques, } \\
\text { telephone support groups (to provide } \\
\text { education, develop skills to manage } \\
\text { troublesome behaviours of dementia, } \\
\text { social support, cognitive reframing, } \\
\text { and strategies for enhancing healthy } \\
\text { behaviours and managing stress) }\end{array}$ & $\begin{array}{l}\text { Carer burden, depression, } \\
\text { social support, self-care }\end{array}$ & $\begin{array}{l}\text { Three ethnic groups were } \\
\text { studied: Hispanics/Latinos } \\
\text { showed less burden, } \\
\text { reduced rates of depression, } \\
\text { greater social support and } \\
\text { self-care; White/Caucasian } \\
\text { participants benefited in } \\
\text { terms of increased support. } \\
\text { All groups showed lower } \\
\text { prevalence of clinical } \\
\text { depression and increased } \\
\text { quality of life }\end{array}$ \\
\hline Onor et al (2007) & $8 / 8$ & $\begin{array}{l}4 \text { months: reality orientation or } \\
\text { reminiscence for patients with } \\
\text { dementia, psychoeducation }\end{array}$ & $\begin{array}{l}\text { Anxiety, depression, carer } \\
\text { burden }\end{array}$ & $\begin{array}{l}\text { Reduced anxiety and } \\
\text { depression; no effect on } \\
\text { burden }\end{array}$ \\
\hline Holland et al (2009) & $\begin{array}{l}224 \text { (multisite variable } \\
\text { interventions: 14/13, 10/9, } \\
\text { 13/11, 12/11, 10/6, 11/6, } \\
28 / 12,11 / 12,34 / 30 \text { ) }\end{array}$ & $\begin{array}{l}\text { 18-month follow-up: REACH } \\
\text { programme }\end{array}$ & $\begin{array}{l}\text { Symptoms of normal and } \\
\text { complicated grief }\end{array}$ & $\begin{array}{l}\text { Lower in carers who had } \\
\text { received intervention }\end{array}$ \\
\hline Lewis et al (2009) & $\begin{array}{l}209 \text { (before and after } \\
\text { study) }\end{array}$ & $\begin{array}{l}9 \text { weeks: Stress-Busting Program, } \\
\text { psychoeducation, support }\end{array}$ & $\begin{array}{l}\text { Perceived stress, depression, } \\
\text { subjective carer burden, } \\
\text { anxiety }\end{array}$ & $\begin{array}{l}\text { Decreased perceived stress; } \\
\text { decreased depression; } \\
\text { reduced subjective burden; } \\
\text { reduced anxiety; reduced } \\
\text { anger; reduced hostility }\end{array}$ \\
\hline $\begin{array}{l}\text { Eloniemi-Sulkava } \\
\text { et al(2009) }\end{array}$ & $63 / 62$ & $\begin{array}{l}24 \text { months: specialist nurse provided } \\
\text { individually tailored interventions; } \\
\text { geriatrician assessment and treatment; } \\
\text { support group }\end{array}$ & $\begin{array}{l}\text { Self-rated health, sleep } \\
\text { quality, physical health, } \\
\text { emotional health }\end{array}$ & Improvement in all domains \\
\hline Gitlin et al (2010) & $137 / 135$ & $\begin{array}{l}24 \text { weeks: combined nursing and } \\
\text { occupational therapy focusing on } \\
\text { patient's problem behaviours }\end{array}$ & $\begin{array}{l}\text { Carer upset, reducing } \\
\text { negative communication, } \\
\text { carer well-being }\end{array}$ & Improvement in all domains \\
\hline $\begin{array}{l}\text { Gallagher-Thompson } \\
\text { et al (2008) }\end{array}$ & $\begin{array}{l}\text { Non-Hispanic White: } \\
50 / 45 \\
\text { Hispanic/Latino: } 47 / 42\end{array}$ & $\begin{array}{l}4 \text { months: Coping with Caregiving } \\
\text { Programme: CBT, psychoeducation, } \\
\text { telecare }\end{array}$ & $\begin{array}{l}\text { Depression, general stress, } \\
\text { stress at problem behaviours } \\
\text { of dementia }\end{array}$ & $\begin{array}{l}\text { Improvement in all domains. } \\
\text { Comparison of Hispanic/ } \\
\text { Latino and non-Hispanic } \\
\text { White carer groups } \\
\text { demonstrated no significant } \\
\text { difference between groups }\end{array}$ \\
\hline $\begin{array}{l}\text { Villareal-Reyna et al } \\
\text { (2012) }\end{array}$ & $\begin{array}{l}\text { CBT mood management: } 10 \\
\text { CBT + humour: } 12 \\
\text { Humour: } 11 \\
\text { Control: } 13\end{array}$ & $\begin{array}{l}8 \text { weeks: } 4 \text { arms: CBT-based mood } \\
\text { management; CBT + use of humour; use } \\
\text { of humour; control }\end{array}$ & Anxiety & $\begin{array}{l}\text { Reduction in anxiety, } \\
\text { greater effect if laughter } \\
\text { intervention used }\end{array}$ \\
\hline Tremont et al (2008) & $16 / 17$ & $\begin{array}{l}12 \text { months: emotional support; directing } \\
\text { carers to resources; encouragement to } \\
\text { attend to own needs; problem-solving } \\
\text { strategies }\end{array}$ & $\begin{array}{l}\text { Perceived burden, stress } \\
\text { related to BPSD, depression }\end{array}$ & $\begin{array}{l}\text { Perceived burden and } \\
\text { stress significantly reduced; } \\
\text { no change in depressive } \\
\text { symptoms }\end{array}$ \\
\hline Chien \& Lee (2011) & $46 / 46$ & $\begin{array}{l}18 \text { months: keyworker allocation; } \\
\text { psychoeducation; personalised support }\end{array}$ & Burden, quality of life & Improvement in both \\
\hline $\begin{array}{l}\text { Meeuwsen et al } \\
\text { (2012) }\end{array}$ & $87 / 88$ & $\begin{array}{l}12 \text { months: post-diagnostic support by } \\
\text { memory clinic } v \text {. that by GP }\end{array}$ & Perceived burden & No improvement \\
\hline Nichols et al(2011) & $\begin{array}{l}\text { Pre-/post-intervention } \\
\text { evaluation: } 129 \text { carers }\end{array}$ & $\begin{array}{l}6 \text { months: home support; telephone } \\
\text { support; group telephone support }\end{array}$ & $\begin{array}{l}\text { Burden, depression, impact } \\
\text { of depression on daily lives, } \\
\text { caregiving frustration }\end{array}$ & Improvement in all domains \\
\hline Waldorff et al (2012) & $167 / 163$ & $\begin{array}{l}12 \text { months: counselling; psychosocial } \\
\text { support; education }\end{array}$ & Depression, quality of life & No significant difference \\
\hline Tanner et al (2015) & $183 / 106$ & $\begin{array}{l}18 \text { months: individualised care } \\
\text { planning; linkage to dementia services; } \\
\text { caregiver education and skill building }\end{array}$ & $\begin{array}{l}\text { Carer burden, depression, } \\
\text { quality of life, number of } \\
\text { unmet needs }\end{array}$ & No significant difference \\
\hline
\end{tabular}

a. A more detailed version of this table appears in the online supplement as Table DS1.

BPSD, behavioural and psychological symptoms of dementia; CBT, cognitive-behavioural therapy; GP, general practitioner; REACH, Resources for Enhancing Alzheimer's Caregiver Health. 
Most of the trials that we identified demonstrated favourable outcomes for carers, which can extend beyond the period of support delivered. For example, a post-study analysis of the Resources for Enhancing Alzheimer's Caregiver Health (REACH) trial (Holland 2009) demonstrated that those supported with a multifaceted intervention while their loved one was alive showed lower symptoms of complicated grief at long-term followup following bereavement.

Larger multicomponent trials have also allowed comparisons across ethnic groups. Belle et al (2006) compared outcomes of a combined education, psychological support and telephonebased intervention across three groups of caregivers in the USA (White/Caucasian; Black/ African American; and Hispanic/Latino). There were some intergroup differences: the Hispanic/ Latino participants showed significant benefit in all measured domains, and the White/Caucasian group gained greater social support. All of the intervention groups showed significant improvement in quality of life, with a lower prevalence of clinical depression.

\section{Other interventions}

Other support interventions that we identified include befriending, exercise and poetry writing.

\section{Befriending}

Third-sector organisations can provide befrienders, who help carers by signposting services and providing emotional support through companionship, conversation and being a 'listening ear'. These services have face validity in improving carers' well-being, health-related quality of life, loneliness and perceived social support, but an RCT involving 236 carers (Charlesworth 2008) failed to demonstrate benefit of befriender services when compared with 'usual care'.

\section{Exercise}

Studies have shown that the benefits of exercise include improved mental and physical health and better sleep. It seems reasonable to assume that these benefits could extend to carers and a few studies have investigated this. In one small RCT (intervention group $n=16$ ), Stella et al (2011) showed that a 6 -month exercise programme for both patients with dementia and their carers decreased neuropsychiatric symptoms and depression in the patients and significantly reduced burden in caregivers. The programme consisted of aerobic and balance exercises for 60 minutes three times a week. The authors attributed the reduction in caregiving burden to an improvement in neuropsychiatric symptoms in the patients. A major strength of the intervention was that it targeted both patients and carers simultaneously, although larger studies with greater power would be required to confirm the results. A similar study (Hirano 2011) showed that moderate exercise three times a week could reduce caregiver burden and improve sleep, although again numbers in the intervention group $(n=17)$ were small. In contrast, a larger RCT $(n=157)$ by Connell $\&$ Janevic (2009) did not demonstrate a significant benefit of exercise for carers in terms of reducing burden, depressive symptoms or perceived stress. At baseline, however, those randomised to the intervention spent significantly greater time exercising than the controls, which may have skewed results. Furthermore, individuals in the intervention group chose their own exercise goals and these varied considerably, which may account for the absence of a significant difference between those exercising and those not. Carbonneau et al (2011) looked at adapting a leisure programme for patients with dementia, with the specific aim of maintaining leisure pursuits in daily life, but failed to quantitatively demonstrate an improvement in caregiver well-being. Although caregivers in the intervention group initially showed an improvement in self-efficacy, this was not sustained.

\section{Poetry}

Kidd et al (2011) reasoned that a simple poetry writing intervention may benefit caregivers by providing a means of expressing some of the challenges they face. Carers were given openended instructions to write poetry over a 4 -week period. Most chose to write about their caregiving situation and expressed an increased sense of acceptance with their caregiving role as a result. However, the results are not generalisable because of the small and homogeneous sample.

\section{Conclusions}

There is a rapidly expanding evidence base for psychosocial interventions to support carers of patients with dementia, but the significant heterogeneity in both the interventions studied and the outcomes measured make drawing generalised conclusions difficult.

Support interventions are more likely to be effective if:

- multiple supports are offered (i.e. a multicomponent approach is taken)

- educational interventions provide opportunity for active learning (e.g. role-play scenarios rather than 'information only') 
- they are simple: the more complicated an intervention is, the less likely a carer is to adhere to it.

Distance interventions can be effective and should be considered, especially for older carers and those in isolated rural locations.

Simply allocating a specific keyworker, supplying written only information or referring on to peer support groups are not likely to be effective.

\section{References}

Acton GJ, Jeonghee K (2001) Interventions to reduce the burden of caregiving for an adult with dementia: a meta-analysis. Research in Nursing and Health, 24: 349-60.

Bartfay E, Bartfay W (2013) Quality-of-life outcomes among Alzheimer's disease family caregivers following community-based intervention. Western Journal of Nursing Research, 35: 98-116.

Belle SH, Burgio L, Burns R, et al (2006) Enhancing the quality of life of dementia caregivers from different ethnic or racial groups: a randomized, controlled trial. Annals of Internal Medicine, 145: 727-38.

Boots LMM, de Vugt ME, van Knippenberg RJM, et al (2014) A systematic review of internet-based supportive interventions for caregivers of patients with dementia. International Journal of Geriatric Psychiatry, 29 : $331-44$.

Carbonneau H, Caron CD, Desrosiers J (2011) Effects of an adapted leisure education program as a means of support for caregivers of people with dementia. Archives of Gerontology and Geriatrics, 53: 31-9.

Charlesworth G, Shepstone L, Wilson E, et al (2008) Befriending carers of people with dementia: randomised controlled trial. BMJ, 336: 1295-7.

Chien WT, Lee IYM (2008) A disease management program for families of persons in Hong Kong with dementia. Psychiatric Services, 59: 433-6. Chien WT, Lee IYM (2011) Randomized controlled trial of a dementia care programme for families of home-resided older people with dementia. Journal of Advanced Nursing, 67: 774-87.

Connell CM, Janevic MR (2009) Effects of a telephone-based exercise intervention for dementia caregiving wives: a randomized controlled trial. Journal of Applied Gerontology, 28: 171-94.

Connor KI, McNeese-Smith DK, Vickrey BG, et al (2008) Determining care management activities associated with mastery and relationship strain for dementia caregivers. Journal of the American Geriatrics Society, 56 : 891-7.

Cooper C, Balamurali TB, Livingston G (2007) A systematic review of the prevalence and covariates of anxiety in caregivers of people with dementia. International Psychogeriatrics, 19: 175-95.

Cooper C, Mukadam N, Katona C, et al (2012) Systematic review of the effectiveness of non-pharmacological interventions to improve quality of life of people with dementia. International Psychogeriatrics, 24: 856-70.

de Rotrou J, Cantegreil I, Faucounau V, et al (2011) Do patients diagnosed with Alzheimer's disease benefit from a psycho-educational programme for family caregivers? A randomised controlled study. International Journal of Geriatric Psychiatry, 26: 833-42.

Dias A, Dewey ME, D'Souza J, et al (2008) The effectiveness of a home care program for supporting caregivers of persons with dementia in developing countries: a randomised controlled trial from Goa, India. PLOS ONE, 3: e2333.

Dröes RM, Meiland FJM, Schmitz MJ, et al (2006) Effect of the Meeting Centres Support Program on informal carers of people with dementia: results from a multi-centre study. Aging and Mental Health, 10: 112-24.

Ducharme FC, Levesque LL, Lachance LM, et al (2011) Learning to become a family caregiver; efficacy of an intervention program for caregivers following diagnosis of dementia in a relative. Gerontologist, 51: 484-94.

Eloniemi-Sulkava U, Saarenheimo M, Laakkonen M-L, et al (2009) Family care as collaboration: effectiveness of a multicomponent support program for elderly couples with dementia. Randomized controlled intervention study. Journal of the American Geriatrics Society, 57: 2200-8.
Finkel S, Czaja SJ, Schulz R, et al (2007) E-care: a telecommunications technology intervention for family caregivers of dementia patients. American Journal of Geriatric Psychiatry, 15: 443-8.

Fortinsky, RH, Kulldorff M, Kleppinger A, et al (2009) Dementia care consultation for family caregivers: collaborative model linking an Alzheimer's Association chapter with primary care physicians. Aging and Mental Health, 13: 162-70.

Gallagher-Thompson D, Dupart H, Jimenez T, et al (2008) Effectiveness of cognitive/behavioral small group intervention for reduction of depression and stress in non-Hispanic White and Hispanic/Latino women dementia family caregivers: Outcomes and mediators of change. Journal of Rational-Emotive and Cognitive-Behavior Therapy, 26: 286-303.

Gallagher-Thompson D, Wang P, Liu W, et al (2010) Effectiveness of a psychoeducational skill training DVD program to reduce stress in Chinese American dementia caregivers: Results of a preliminary study. Aging and Mental Health, 14: 263-73.

Gant JR, Steffen AM, Lauderdale SA (2007) Comparative outcomes of two distance-based interventions for male caregivers of family members with dementia. American Journal of Alzheimer's Disease and Other Dementias, 22: 120-8.

Gitlin LN, Winter L, Dennis MP, et al (2010) Targeting and managing behavioral symptoms in individuals with dementia: a randomized trial of a nonpharmacological intervention. Journal of the American Geriatrics Society, 58: 1465-74.

Gitlin LN, Marx K, Stanley IH, et al (2015) Translating evidence-based dementia caregiving interventions into practice: state-of-the-science and next steps. Gerontologist, 55: 210-26.

Glueckauf RL, Davis WS, Willis F, et al (2012) Telephone-based, cognitivebehavioral therapy for African American dementia caregivers with depression: initial findings. Rehabilitation Psychology, 57: 124-39.

Hepburn K, Lewis M, Tornatore J, et al (2007) The Savvy Caregiver program: the demonstrated effectiveness of a transportable dementia caregiver psychoeducation program. Journal of Gerontological Nursing, 33(3): 30-6.

Hirano A, Suzuki Y, Kuzuya M (2011) Influence of regular exercise on subjective sense of burden and physical symptoms in communitydwelling caregivers of dementia patients: a randomized controlled trial. Archives of Gerontology and Geriatrics, 53: e158-63.

Holland JM, Currier JM, Gallagher-Thompson D (2009) Outcomes from the Resources for Enhancing Alzheimer's Caregiver Health (REACH) program for bereaved caregivers. Psychology and Aging, 24: 190-202.

Joling KJ, van Marwijk HW, van der Horst HE (2012) Effectiveness of family meetings for family caregivers on delaying time to nursing home placement of dementia patients: a randomized trial. PLOS ONE, 7: e42145.

Kidd LI, Zauszniewski JA, Morris DL (2011) Benefits of a poetry writing intervention for family caregivers of elders with dementia. Issues in Mental Health Nursing, 32: 598-604.

Kurz A, Wagenpfeil S, Hallauer J, et al (2010) Evaluation of a brief educational program for dementia carers: the AENEAS study. International Journal of Geriatric Psychiatry, 25: 861-9.

Lam LCW, Lee JSW, Chung JCC, et al (2010) A randomized controlled trial to examine the effectiveness of case management model for community dwelling older persons with mild dementia in Hong Kong. International Journal of Geriatric Psychiatry, 25: 395-402.

Lewis SL, Miner-Williams D, Novian A, et al (2009) A stress-busting program for family caregivers. Rehabilitation Nursing Journal, 34: 151-9.

Liddle J, Smith-Conway ER, Baker R, et al (2012) Memory and communication support strategies in dementia: effect of a training program for informal caregivers. International Psychogeriatrics, 24: 1927-42.

Livingston G, Barber J, Rapaport P, et al (2013) Clinical effectiveness of a manual based coping strategy programme (START, STrAtegies for RelaTives) in promoting the mental health of carers of family members with dementia: pragmatic randomised controlled trial. BMJ, 347: f6276.

Livingston G, Barber J, Rapaport P, et al (2014) Long-term clinical and cost-effectiveness of psychological intervention for family carers of people with dementia: a single-blind, randomised, controlled trial. Lancet Psychiatry, 1: 485-576.

\section{MCO answers \\ 1 e $\quad 2$ b $\quad 3 a \quad 4 b \quad 5 a$

ba


Losada AM-G, Márquez-González M, Romero-Moreno R (2011) Mechanisms of action of a psychological intervention for dementia caregivers: effects of behavioral activation and modification of dysfunctional thoughts. International Journal of Geriatric Psychiatry, 26: 1119-27.

Márquez-González M, Losada A, Izal M, et al (2007) Modification of dysfunctional thoughts about caregiving in dementia family caregivers: description and outcomes of an intervention programme. Aging and Mental Health, 11: 616-25.

Meeuwsen EJ, Melis RJ, Van Der Aa GC, et al (2012) Effectiveness of dementia follow-up care by memory clinics or general practitioners: randomised controlled trial. BMJ, 344: e3086.

Mittelman MS, Roth DL, Clay OJ, et al (2007) Preserving health of Alzheimer caregivers: impact of a spouse caregiver intervention. American Journal of Geriatric Psychiatry, 15: 780-9.

Mittelman MS, Brodaty H, Wallen AS, et al (2008) A three-country randomized controlled trial of a psychosocial intervention for caregivers combined with pharmacological treatment for patients with Alzheimer disease: effects on caregiver depression. American Journal of Geriatric Psychiatry, 16: 893-904

National Institute for Health and Care Excellence (2006) Dementia: Supporting People with Dementia and their Carers in Health and Social Care (Updated 2016) (Clinical Guideline CG42). NICE.

Nichols LO, Martindale-Adams J, Burns R, et al (2011) Translation of a dementia caregiver support program in a health care system - REACH VA. Archives of Internal Medicine, 171: 353-9.

Onor ML, Trevisiol M, Negro C, et al (2007) Impact of a multimodal rehabilitative intervention on demented patients and their caregivers. American Journal of Alzheimer's Disease and Other Dementias, 22: 261-72.

Pinquart M, Sorensen S (2003) Differences between caregivers and noncaregivers in psychological health and physical health: a metaanalysis. Psychology and Aging, 18: 250-67.

Simpson R, Wakefield P, Spiers N, et al (2006) Carer-held records for dementia: a controlled trial. International Psychogeriatrics, 18: 259-68.

Spijker A, Wollersheim H, Teerenstra S, et al (2011) Systematic care for caregivers of patients with dementia: a multicenter, cluster-randomized, controlled trial. American Journal of Geriatric Psychiatry, 19: 521-31.
Stella F, Canonici AP, Gobbi S, et al (2011) Attenuation of neuropsychiatric symptoms and caregiver burden in Alzheimer's disease by motor intervention: a controlled trial. Clinics, 66: 1353-60.

Tanner JA, Black BS, Johnston D (2015) A randomized controlled trial of a community-based dementia care coordination intervention: effects of MIND at Home on caregiver outcomes. American Journal of Geriatric Psychiatry, 23: 391-402.

Tremont G, Davis JD, Bishop DS (2008) Telephone-delivered psychosocial intervention reduces burden in dementia caregivers. Dementia, 7: 503-

Tremont G, Davis JD, Papandonatos GD, et al (2015) Psychosocial telephone intervention for dementia caregivers: a randomized, controlled trial. Alzheimer's \& Dementia, 11: 541-8.

Ulstein I, Sandvik L, Wyller T, et al (2007) A one-year randomized controlled psychosocial intervention study among family carers of dementia patients: effects on patients and carers. Dementia and Geriatric Cognitive Disorders, 24: 469-75.

van Mierlo LD, Meiland FJ, Dröes RM (2012) Dementelcoach: effect of telephone coaching on carers of community-dwelling people with dementia. International Psychogeriatrics, 24: 212-22

Villareal-Reyna M, Salazar-Gonzalez BC, Cruz-Quevedo JE, et al (2012) Outcomes of interventions for Alzheimer's family caregivers in Mexico. Western Journal of Nursing Research, 34: 973-90.

Waldorff FB, Buss DV, Eckermann A, et al (2012) Efficacy of psychosocial intervention in patients with mild Alzheimer's disease: the multicentre, rater blinded, randomised Danish Alzheimer Intervention Study (DAISY). BMJ, 345: e4693

Wang LO (2011) Randomised controlled trial of a family-led mutual support programme for people with dementia. Journal of Clinical Nursing, 20: 2362-6.

Winter L, Gitlin LN (2007) Evaluation of a telephone-based support group intervention for female caregivers of community-dwelling individuals with dementia. American Journal of Alzheimer's Disease and Other Dementias, 21: 391-7.

Zhu CW, Scarmeas N, Ornstein K, et al (2015) Health-care use and cost in dementia caregivers: Iongitudinal results from the Predictors Caregiver Study. Alzheimer's \& Dementia, 11: 444-54.

\section{MCOs}

Select the single best option for each question stem

\section{Regarding the evidence base for supports} for carers of people with dementia:

a drawing generalised conclusions regarding their effectiveness is easy

b longer, complex interventions are more effective than short, simple interventions

c there is no evidence that distance-based interventions are effective

d referring carers to Alzheimer's UK groups is the only thing you can do

e a combination of different interventions at different times is most effective.

\section{Education groups for carers:}

a should provide support over several months

b should promote active learning

c that have culturally sensitive adaptations are no more effective than standard groups

$\mathrm{d}$ are less effective for male carers

e have been shown to reduce rates of depression in carers.
3 As regards formal approaches to care:

a they include care management, care programming and specialist nurses to deliver care

b formal care management has consistent evidence of effectiveness

c use of a protocol to trigger appropriate care pathways for carers can reduce carer anxiety

d caregiver-held records can reduce carer anxiety

e regular care meetings have been shown to reduce depression in carers.

4 As regards use of telecare for carers of people with dementia:

a use of technology to support older carers does not work

b providing telephone support to carers can be effective in reducing carer stress

c telecare is not effective in providing support to male carers

$d$ there is strong evidence that computer-based supports decrease perceived burden in carers

e there is no evidence that skills-training DVDs are helpful.
5 As regards multicomponent interventions for carers:

a they may include combinations of support, education, counselling and psychology

b trials are too small to generalise results

c interventions are too complicated and expensive to work

$d$ the evidence suggests that the most effective combination includes psychoeducation and CBT

e they do not reduce burden of caring in Latino caregivers. 